\title{
Health care quality from the patients' perspective: a comparative study between an old and a new, high-tech hospital
}

This article was published in the following Dove Press journal: Journal of Multidisciplinary Healthcare

\author{
Vigdis Abrahamsen \\ Grøndahl' \\ Jörg W Kirchhoff' \\ Kirsti Lauvli Andersen' \\ Lise Aagaard Sørby ${ }^{2}$ \\ Hilde Marie Andreassen' \\ Eli-Anne Skaug' \\ Anne Karine Roos ${ }^{2}$ \\ Liv Solveig Tvete' \\ Ann Karin Helgesen' \\ 'Faculty of Health and Welfare, \\ Østfold University College, Halden, \\ Norway; ${ }^{2}$ Østfold Hospital Trust, \\ Grålum, Norway
}

Purpose: Previous studies show that the hospital environment and the behavior of health care personnel may predict patients' perceptions of care quality. The aim of the study was to explore changes in perceived care quality from the patients' perspective (QPP) when hospital services are relocated from an old to a new high-tech hospital and to describe what is important for patients in the high-tech hospital.

Patients and methods: A comparative cross-sectional design was used. The questionnaire QPP, which is based on a theoretical model of the quality of care comprising four quality dimensions, was used. Data were collected in 2015 (old hospital) and 2016 (new hospital), with 253 and 324 respondents, respectively, by consecutive sampling. Comparative statistics was used to test differences between patients' care quality perceptions (perceived reality [PR] and subjective importance $[\mathrm{SI}])(P \leq 0.05)$.

Results: The patients rated PR of all four quality dimensions (the care organization's physicaltechnical conditions and sociocultural approach and the caregivers' medical-technical competence and identity-oriented approach) higher in the new hospital. However, only the two quality dimensions concerning the care organization were rated significantly more highly. On an item level, five of the 27 items scored significantly higher on patients' SI than on patients' PR of the care in the new hospital, indicating a quality deficiency from the patients' perspective. This comprised receiving effective pain relief, receiving examination and treatment within an acceptable waiting time, receiving useful information on self-care, receiving useful information on which doctors were responsible for their medical care, and having a comfortable bed.

Conclusion: The increase in care QPP was associated with improved environmental conditions, and no significant improvement in care quality was associated with the health care personnel. The results indicate that being in a high-tech environment does not improve patients' perceptions of care quality provided by health care personnel. The results gave valuable information for quality improvement in clinical practice, based on the patients' perspective.

Keywords: high-tech hospital, patients' subjective importance, patients' perceived reality, quality of care, QPP questionnaire

\section{Introduction}

Patients' perceptions of care quality are one of the essential indicators of care quality, and as such important for quality improvement work. ${ }^{1-3}$ Patients in need of health care services wish for individualized, high-quality care, which is also the main goal for those providing the care. ${ }^{2,4,5}$ Patients' individual perceptions of care quality are important, because they may reflect patients' perceptions of standards in hospital wards ${ }^{6}$ and also clarify how patients define quality. ${ }^{7}$ The theoretical model of quality of care: The Quality
Correspondence: Vigdis Abrahamsen Grøndahl

Faculty of Health and Welfare, Østfold University College, 1757 Halden, Norway Tel +479305 2634

Email vigdis.a.grondahl@hiof.no 
of Care from the Patients' Perspective (QPP) views care quality through the patient's eyes and is used as the theoretical foundation in this study. ${ }^{8}$ Quality of care in the QPP model is seen as a measure of patients' experiences of the quality of health care encountering patients' perceived reality (PR) ${ }^{8}$ Patients' perceptions of what constitutes quality of care are formed by their system of norms, expectations, and experiences and by their encounter with an existing care structure. ${ }^{8}$

Previous research has shown that different factors may impact on the patients' perceptions of care quality. These factors can be classified into the following two broad areas: person-related conditions and external objective care conditions. Person-related conditions, such as the patients' sex, ${ }^{9,10}$ age, ${ }^{9,11}$ educational level, ${ }^{9,10}$ self-reported physical health and psychological well-being, ${ }^{12,13}$ and whether the patients are admitted to hospital as emergencies or by schedule, ${ }^{9,10}$ are found to be connected with patients' perceptions of care quality.

External objective care conditions connected with patients' perceptions of care quality are as follows: the hospital's organization and structure of care, ${ }^{14-16}$ the competence of health care personnel, ${ }^{17-19}$ the nurse-physician relationship, ${ }^{20}$ the general atmosphere on the wards, ${ }^{4}$ the size of the hospital, ${ }^{9}$ the number of beds on each ward, ${ }^{21}$ inpatient stay, ${ }^{22}$ and occupancy. ${ }^{21}$ In addition, a comfortable environment, comprising such aspects as hotel services ${ }^{18}$ and staying in newer hospital buildings, ${ }^{23}$ has a positive impact on patients' quality ratings. Patients have also identified cleanliness, good signs/information points, adequate seating, nonovercrowding, and privacy for conversations as important when they are hospitalized. ${ }^{24}$ One recent study explored changes in patient's satisfaction when clinical services were relocated to a new clinical building with patient-centered features. ${ }^{25}$ The increase in satisfaction was associated with improved room and visitor-related facilities such as pleasant décor, visitor accommodation, and comfort. However, no significant improvement in satisfaction with clinical providers or ancillary staff was found. ${ }^{25}$

As described earlier, previous research focuses on the impact of patients' person-related and external objective conditions on their quality of care perceptions. However, few studies explore the role of the high-tech hospital environment and patients' perception of care quality. Furthermore, research investigating what patients view as being important for experiencing high care quality in high-tech hospitals is scarce.

The aim of the study was to explore changes in perceived care QPP when hospital services are relocated from an old to a new high-tech hospital and to describe what is important to patients in the high-tech hospital.

\section{Methods \\ Design}

The design was comparatively cross-sectional to explore patient's perceptions of care quality.

\section{Setting}

A Norwegian hospital trust was relocated to a new clinical building in November 2015. The hospital serves approximately 290,000 people and is viewed as a medium-sized hospital in Norway. However, the number of emergency beds makes the hospital the fourth largest emergency hospital in Norway. The hospital has also been recognized as a showcase of best practice in the implementation of health care information technology and placed in Europe's Electronic Medical Record Adoption Model (EMRAM) Stage 6 of the 7 Stages Club by Healthcare Information and Management Systems Society (HIMSS) Europe, which is an organization that assesses and scores the clinical information technology systems in European hospitals. ${ }^{26}$

In the old hospital, the number of beds on the wards varied between 14 and 30, depending on the architectural conditions of the building. There were mostly multibedded patient rooms with shared bathrooms, and single rooms were scarce on each ward. Each ward also had one living room with a television for the patients to use and a kitchen for preparing small extra meals if needed. The new hospital consists solely of single-bed rooms with private bathrooms and television. The wards in the new hospital are standardized to 36 beds organized in four bed courts consisting of nine beds located around a working station. On every ward, there is a dining room with buffet dining for the patients.

In addition to new physical buildings, the relocation should comprise a reorganization of staff's working methods and services because of the increased implementation of technology. The technology was applied in order to streamline the hospital systems, so that the patients would have fewer staff to interact with throughout their stay. It includes electronic whiteboards, which allow patient self-check and ensure coordination and logistics of inpatients. It also includes a system for message alerts using smart phones facilitating easy and rapid communication across disciplines and clinical units. Using mobile solutions such as tablets and smart phones, doctors and nurses have real-time information where they need it. Advanced logistics systems have also been introduced in the new hospital. Blood samples and medicines are transported 
in pneumatic tubes, while automatic guided vehicles (AGVs) transport clothes, foods, and merchandise. These systems contribute to more efficient logistics while relieving health professionals from this job, allowing them the possibility of spending more quality time with the patients.

\section{Participants and procedure}

The population consisted of patients ready for discharge from hospital wards during 2 weeks in the autumn of 2015 (old hospital) and autumn of 2016 (new hospital). Consecutive sampling was used. Patients were included if 1) they were 18 years or older, 2) they understood Norwegian, 3) they were able to express themselves verbally, and 4) their mental and physical health were such that it was ethically justifiable to invite them to participate. The responsible nurse on each ward assessed the patients according to these inclusion criteria.

On the day of the patient's discharge or the day before, the contact person (nurse or secretary) on each ward/bed court gave patients, who satisfied the inclusion criteria, both oral and written information about the study. Patients who agreed to take part in the study received the questionnaire. Patients were instructed to return their completed questionnaire in a sealed envelope to the contact person before discharge. Patients who were not physically able to fill in the answers were offered assistance by one of the researchers in the research team. The researchers collected the envelopes daily during the 2 weeks of the data collection period. A total of 253 patients answered the questionnaire in the old hospital, and 324 patients answered the questionnaire in the new hospital, that is, 22 and $28.4 \%$ of discharged patients, respectively.

\section{Data collection - the questionnaire}

The respondents' perceptions of care quality were measured using the QPP questionnaire, ${ }^{27}$ including one item concerning information on the use and effects of medicines. ${ }^{10}$ Furthermore, two items about fellow patients were included. The questionnaire is patient centered and derived from a theoretical model of quality of care; The Quality of Care from the Patients' Perspective. ${ }^{27}$ The model states that patients' perceptions of what constitutes quality of care are formed by their system of norms, expectations, and experiences and by their encounter with an existing care structure. Hence, the patients' perception of care quality includes four dimensions and the questionnaire consists of 27 items covering the caregiver's medical-technical competence, the caregiver's identity-oriented approach, the care organization's physicaltechnical conditions, and the care organization's sociocultural atmosphere.
Each item was evaluated in two ways by the respondents: the perceived reality $(\mathrm{PR})$ of the item and the subjective importance (SI) of the item. ${ }^{27}$ Each item's PR described how the respondent experienced various aspects of care. Items were evaluated with sentences related to the statement "This is what I experienced", for example, "My care was determined by my own requests and needs rather than the staff's procedure". A 4-point response scale ranging from 1 (do not agree at all) to 4 (completely agree) was used. Each item also had a "not applicable" response. The SI of each item described how important patients considered various aspects of care to be and described their preferences. Items were evaluated with sentences related to the statement "This is how important it was for me", for example "The nurses showed commitment: "cared about me"'. A 4-point response scale ranging from 1 (little or no importance) to 4 (very highest importance) was used. Each item also had a not applicable response. The index of each dimension was calculated by adding the item scores and dividing the sum by the number of items answered within that dimension. The Cronbach's $\alpha$ coefficients for PR in this study were $0.66 / 0.78$ for medical-technical competence, 0.90/0.90 for identity-oriented approach, 0.54/0.62 for physical-technical conditions, and 0.79/0.89 for sociocultural atmosphere for 2015 and 2016, respectively. The Cronbach's $\alpha$ coefficients for SI were $0.75 / 0.78$ for medical-technical competence, $0.87 / 0.91$ for identity-oriented approach, $0.77 / 0.76$ for physical-technical conditions, and 0.82/0.90 for sociocultural atmosphere.

An Index of Measures (Figure 1) was developed by Larsson and Wilde-Larsson ${ }^{28}$ based on scores on the item's PR and SI at the group level. The idea behind the Index is that various combinations of responses to questions on PR and SI should prompt different measures on the part of the caregivers. ${ }^{28}$

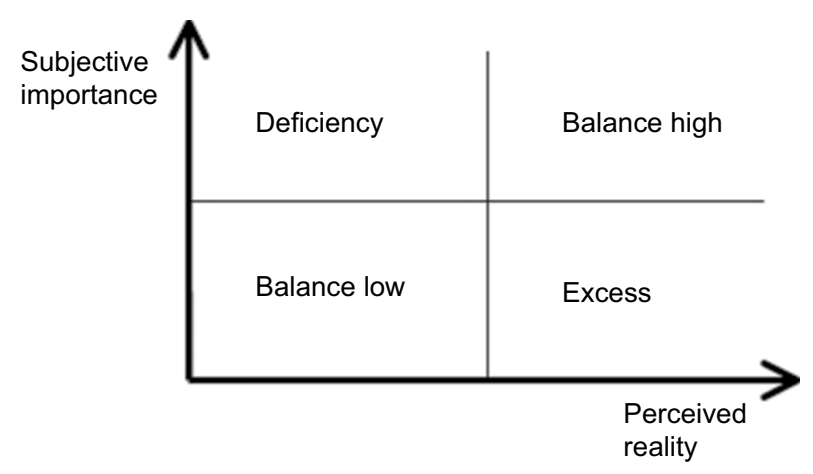

Figure I Illustration of the Index of Measures (Larsson and Wilde-Larsson, 2003). ${ }^{28}$ 
Care QPP is considered to be high when PR scores are higher than scores on SI and also when both scores on PR and SI are high and in balance. Previous studies have argued that high scores on QPP items range from about 3.30 to 4.0. ${ }^{29,30}$ Care quality is considered deficient from the patient's perspective when scores on SI are higher than scores on PR. Finally, care quality is considered low when the balance is low on both SI and PR. Scores ranging between 3.30 and 3.00 are considered a modest rating, ${ }^{29}$ and scores ranging from 3.00 and lower are considered a low quality rating..$^{29,30}$

The questionnaire also included the respondents' sociodemographic characteristics and health-related aspects comprising the following eight items: age, sex, education, inpatient stay, and respondent's self-rated health condition in response to "How would you describe your present physical health condition?" and "How would you describe your present psychological well-being?" using a 5-point scale ranging from 1 (very poor) to 5 (very good). In addition, the respondents were asked about hospital admission ("scheduled" or "emergency"). In 2015, the respondents were asked whether they stayed in single rooms, multiple bed rooms, or the corridor. In 2016, the new hospital only had single rooms, consequently the question was changed, and the respondents were asked whether they stayed in single rooms or in a corridor during their stay. The questionnaire consisted of a total of 35 items.

\section{Statistical analyses}

Data were analyzed using SPSS Version 24.0 (IBM Corporation, Armonk, NY, USA). ${ }^{31}$ The descriptive statistics frequency, percentage, mean, and standard deviation were used to describe the study sample and the respondents' perceptions of quality of care, the PR and SI. Independent sample's $t$-test was run on continuous variables, and Chi-squared test was run on categorical variables to explore potential differences in characteristics between the patient groups in the old and the new hospitals. The Mann-Whitney $U$-test was used to compare differences between the respondents' care quality perceptions in the old and the new hospitals. Wilcoxon signed-rank test was used to test for potential differences between PR and SI in the 2016 sample (the new hospital). The Cronbach's $\alpha$ was used to test the quality scales for internal consistency. ${ }^{32,33}$ Statistical significance was set at $P \leq 0.05$.

\section{Results}

\section{Respondent characteristics}

The characteristics of the two samples did not differ apart from significantly more men answering the questionnaire compared to women answering the questionnaire in the new hospital (2016). The median age in 2015 was 61 years, and the median age in 2016 was 65 years. Most respondents were admitted to hospital as emergencies. They rated their psychological well-being better than their physical health. The number of patients staying in a corridor in the new hospital was unchanged from the old hospital (refer Table 1 for results).

\section{The respondents' Index of Measures}

Table 2 displays the respondents' PR and SI at dimension level. In the old hospital, there was a care quality deficit in the two dimensions associated with the health care personnel. No care quality deficits were shown at dimension level in the new hospital. This indicates a balance between what is of importance to the respondents and how they experience the care quality while hospitalized. The scores on the PR of the dimensions associated with the care environment were significantly higher in the new hospital than in the old hospital. In addition, the scores on the SI of the physical-technical dimension were significantly higher in the new hospital than in the old hospital.

\section{The respondents' perceptions of care quality in the old hospital compared with the new hospital}

Table 3 displays the comparison of the respondents' scores on PR and on SI on item level in the old and in the new hospitals, respectively. In addition, Table 3 shows the items with significantly different scores on PR from the old to the new hospital and significantly different scores on SI from the old to the new hospital. A total of 17 items showed statistically significant higher scores on PR in the new hospital compared with the old hospital, and no items were scored significantly lower. As for SI, five items were scored significantly higher in the new hospital than in the old hospital.

In the new hospital, a total of 12 items showed statistically significant differences in PR and SI scores. On five of these items, the respondents' scores on SI are higher than the PR scores, which show a care quality deficient. On seven of these items, the respondents' scores on PR are higher than the scores on SI and display a high-quality balance (refer Table 3 for all results).

\section{Discussion}

Patients' perceived care quality increased from the old to the new hospital in all four quality dimensions (the care environment's physical-technical conditions and sociocultural atmo- 
Table I Respondents' characteristics in the old hospital $(\mathrm{N}=253)$ compared with the new hospital $(\mathrm{N}=324)$

\begin{tabular}{|c|c|c|c|c|c|}
\hline \multirow[t]{2}{*}{ Variable } & \multicolumn{2}{|c|}{ Old hospital - 2015, N=253 } & \multicolumn{2}{|c|}{ New hospital $-2016, N=324$} & \multirow[t]{2}{*}{$P$-value } \\
\hline & $\%$ & Mean/SD & $\%$ & Mean/SD & \\
\hline Age (years) & & $\begin{array}{l}58.0 / 20.9 \\
\text { Range } \\
18-98\end{array}$ & & $\begin{array}{l}61.1 / 18.0 \\
\text { Range } \\
18-97\end{array}$ & 0.65 \\
\hline Sex & & & & & $0.026^{\mathrm{a}}$ \\
\hline Men & 37.8 & & 47.5 & & \\
\hline Women & 62.2 & & 52.5 & & \\
\hline Education level & & & & & 0.26 \\
\hline Compulsory school & 24.5 & & 28.9 & & \\
\hline Upper secondary school & 47.4 & & 40.6 & & \\
\hline University & 28.1 & & 30.5 & & \\
\hline \multicolumn{6}{|l|}{ Health conditions } \\
\hline $\begin{array}{l}\text { Self-reported physical } \\
\text { health condition }\end{array}$ & & $3.41 / 1.0$ & & $3.50 / 0.9$ & 0.31 \\
\hline $\begin{array}{l}\text { Self-reported } \\
\text { psychological well-being }\end{array}$ & & $3.90 / 0.9$ & & $4.02 / 0.9$ & 0.13 \\
\hline Admission type & & & & & 0.69 \\
\hline Scheduled & 28.2 & & 30.2 & & \\
\hline Emergency & 71.8 & & 69.9 & & \\
\hline In-patient stay & & $5.52 / 7.4$ & & $5.40 / 7.0$ & 0.84 \\
\hline \multicolumn{6}{|l|}{ Accommodation } \\
\hline Single room & 24.1 & & 90.5 & & $0.00 I^{\mathrm{a}}$ \\
\hline Sharing room & 65.1 & & - & & $0.00 \mathrm{I}^{\mathrm{a}}$ \\
\hline Corridor & 10.8 & & 9.5 & & 0.43 \\
\hline
\end{tabular}

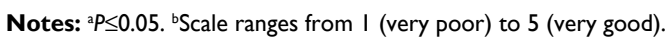

Table 2 The respondents' Index of Measures (the difference between PR and SI at dimension level) in the old hospital and in the new hospital, respectively

\begin{tabular}{|c|c|c|c|c|c|c|c|c|}
\hline \multirow{2}{*}{$\begin{array}{l}\text { Care quality } \\
\text { dimensions }\end{array}$} & \multicolumn{4}{|c|}{ Old hospital - 2015, N=253 } & \multicolumn{4}{|c|}{ New hospital $-2016, N=324$} \\
\hline & $\begin{array}{l}\text { PR }^{\mathbf{a}} \text { (Mean/ } \\
\text { SD) }\end{array}$ & SI ${ }^{\mathrm{b}}($ Mean/SD $)$ & $P$-value & $\begin{array}{l}\text { Index of } \\
\text { Measures }\end{array}$ & $\begin{array}{l}\text { PR }^{\mathrm{a}} \text { (Mean/ } \\
\text { SD) }\end{array}$ & $\begin{array}{l}\text { SIb (Mean/ } \\
\text { SD) }\end{array}$ & $P$-value & $\begin{array}{l}\text { Index of } \\
\text { Measures }\end{array}$ \\
\hline $\begin{array}{l}\text { Medical-technical } \\
\text { competence }\end{array}$ & $3.43 / 0.57$ & $3.55 / 0.48$ & $0.002^{c}$ & Deficiency & $3.54 / 0.59$ & $3.58 / 0.48$ & 0.63 & $\begin{array}{l}\text { Balance } \\
\text { high }\end{array}$ \\
\hline $\begin{array}{l}\text { Identity-oriented } \\
\text { approach }\end{array}$ & $3.34 / 0.58$ & $3.50 / 0.45$ & $0.004^{c}$ & Deficiency & $3.42 / 0.55$ & $3.44 / 0.49$ & 0.49 & $\begin{array}{l}\text { Balance } \\
\text { high }\end{array}$ \\
\hline $\begin{array}{l}\text { Physical-technical } \\
\text { conditions }\end{array}$ & $3.23 / 0.66^{d}$ & $3.27 / 0.65^{\mathrm{e}}$ & 0.28 & Balance low & $3.50 / 0.62^{d}$ & $3.43 / 0.56^{\mathrm{e}}$ & 0.07 & $\begin{array}{l}\text { Balance } \\
\text { high }\end{array}$ \\
\hline $\begin{array}{l}\text { Sociocultural } \\
\text { atmosphere }\end{array}$ & $3.21 / 0.67^{d}$ & $3.22 / 0.63$ & 0.47 & Balance low & $3.54 / 0.57^{d}$ & $3.32 / 0.70$ & 0.27 & $\begin{array}{l}\text { Balance } \\
\text { high }\end{array}$ \\
\hline
\end{tabular}

Notes: a Scale could range from I (do not agree at all) to 4 (completely agree). 'SCale could range from I (little or no importance) to 4 (very highest importance). 'P $\leq 0.05$. dPR scores 2015 were significantly lower than PR scores 2016. ESI scores 2015 were significantly lower than SI scores 2016.

Abbreviations: PR, perceived reality; SI, subjective importance.

sphere and the care personnel's medical-technical competence and identity-oriented approach) without a decrease in their scores on the SI of the care quality. This indicates that the quality of the health care received by the patients in the new hospital had increased and was in balance. ${ }^{28}$ The two care quality environment dimensions' physical-technical conditions and sociocultural atmosphere received significantly higher scores in the new hospital than in the old hospital. This is in line with results of a previous study that found that changes in patient satisfaction after hospital renovation were associated with improved room- and visitor-related satisfaction. ${ }^{25}$ Previous results also show that patients with favorable impressions of the building design fared better on well-being-related outcomes relative to those with less favorable impressions ${ }^{23}$ and that the environment has a greater influence on patient's satisfaction than just being clean and quiet. ${ }^{34}$ 
Table 3 Respondents' PR and SI at item level in the old (20I5) and the new high-tech hospital (20I6), respectively

\begin{tabular}{|c|c|c|c|c|c|c|}
\hline \multirow[t]{2}{*}{ Care quality } & \multicolumn{3}{|c|}{ Old hospital - 2015, N=253 } & \multicolumn{3}{|c|}{ New hospital $-2016, N=324$} \\
\hline & $\begin{array}{l}\text { PR }^{\text {a }} \text { (Mean/ } \\
\text { SD) }\end{array}$ & $\begin{array}{l}\text { SIb } \\
\text { (Mean/ } \\
\text { SD) }\end{array}$ & $P$-value ${ }^{c}$ & $\begin{array}{l}\text { PR }^{\text {a }}(\text { Mean/ } \\
\text { SD) }\end{array}$ & $\begin{array}{l}\text { SIb } \\
\text { (Mean/ } \\
\text { SD) }\end{array}$ & P-value \\
\hline $\begin{array}{l}\text { Medical-technical } \\
\text { competence } \\
\text { dimension }\end{array}$ & $3.43 / 0.57$ & $3.55 / 0.48$ & $0.002^{c}$ & $3.54 / 0.59$ & $3.58 / 0.48$ & 0.63 \\
\hline $\begin{array}{l}\text { Best possible physical } \\
\text { care }\end{array}$ & $3.22 / 0.92^{d}$ & $3.42 / 0.69$ & $0.002^{c}$ & $3.46 / 0.8 I^{d}$ & $3.40 / 0.75$ & 0.19 \\
\hline $\begin{array}{l}\text { Best possible medical } \\
\text { care }\end{array}$ & $3.54 / 0.73^{d}$ & $3.69 / 0.50$ & $0.005^{c}$ & $3.69 / 0.63^{d}$ & $3.70 / 0.54$ & 0.68 \\
\hline Effective pain relief & $3.47 / 0.79$ & $3.57 / 0.67$ & 0.12 & $3.49 / 0.79$ & $3.63 / 0.57$ & $0.006^{c}$ \\
\hline $\begin{array}{l}\text { Examinations and } \\
\text { treatments within } \\
\text { acceptable waiting time }\end{array}$ & $3.40 / 0.78$ & $3.49 / 0.67$ & 0.43 & $3.42 / 0.85$ & $3.54 / 0.61$ & $0.0 I^{c}$ \\
\hline $\begin{array}{l}\text { Identity-oriented } \\
\text { approach dimension }\end{array}$ & $3.34 / 0.58$ & $3.50 / 0.45$ & $0.004^{c}$ & $3.42 / 0.55$ & $3.44 / 0.49$ & 0.49 \\
\hline $\begin{array}{l}\text { Information on } \\
\text { examinations and } \\
\text { treatments }\end{array}$ & $3.28 / 0.86$ & $3.42 / 0.73$ & $0.032^{c}$ & $3.44 / 0.83$ & $3.37 / 0.70$ & 0.07 \\
\hline $\begin{array}{l}\text { Information on the } \\
\text { results of examinations } \\
\text { and treatments }\end{array}$ & $3.38 / 0.82$ & $3.57 / 0.64$ & $0.00 I^{c}$ & $3.42 / 0.81$ & $3.50 / 0.63$ & 0.18 \\
\hline Information on self-care & $3.00 / 1.0$ & $3.21 / 0.83$ & $0.00 I^{c}$ & $3.08 / 0.97$ & $3.18 / 0.83$ & $0.043^{c}$ \\
\hline $\begin{array}{l}\text { Information on } \\
\text { responsible doctors }\end{array}$ & $2.58 / 1.2^{\mathrm{d}}$ & $3.03 / 1.0$ & $<0.00 I^{\mathrm{c}}$ & $2.84 / 1.1^{d}$ & $3.05 / 0.96$ & $0.00 I^{c}$ \\
\hline $\begin{array}{l}\text { Information on } \\
\text { responsible nurses }\end{array}$ & $2.88 / I . I^{d}$ & $3.08 / 0.98$ & $0.034^{c}$ & $3.07 / 1 . I^{d}$ & $3.08 / 0.94$ & 0.62 \\
\hline $\begin{array}{l}\text { Participate in the } \\
\text { decisions applied to my } \\
\text { care }\end{array}$ & $3.05 / 1.0^{d}$ & $3.28 / 0.85$ & $<0.001^{\mathrm{c}}$ & $3.42 / 0.82^{d}$ & $3.34 / 0.83$ & 0.18 \\
\hline $\begin{array}{l}\text { Doctors showed } \\
\text { commitment }\end{array}$ & $3.44 / 0.82$ & $3.50 / 0.7 I$ & 0.31 & $3.52 / 0.77$ & $3.55 / 0.66$ & 0.80 \\
\hline $\begin{array}{l}\text { Nurses and assistant } \\
\text { nurses showed } \\
\text { commitment }\end{array}$ & $3.58 / 0.69^{d}$ & $3.61 / 0.65$ & 0.68 & $3.72 / 0.56^{d}$ & $3.59 / 0.59$ & $<0.00 I^{\mathrm{c}}$ \\
\hline $\begin{array}{l}\text { Doctors understood my } \\
\text { situation }\end{array}$ & $3.24 / 0.96$ & $3.44 / 0.77$ & $<0.001^{\mathrm{c}}$ & $3.38 / 0.87$ & $3.45 / 0.74$ & 0.30 \\
\hline $\begin{array}{l}\text { Nurses and assistant } \\
\text { nurses understood my } \\
\text { situation }\end{array}$ & $3.38 / 0.85^{d}$ & $3.50 / 0.7 I$ & $0.04 I^{c}$ & $3.59 / 0.67^{d}$ & $3.52 / 0.64$ & 0.09 \\
\hline Doctors were respectful & $3.7 \mathrm{I} / 0.59$ & $3.69 / 0.56$ & 0.58 & $3.76 / 0.58$ & $3.63 / 0.61$ & $<0.00 \mathrm{I}^{\mathrm{c}}$ \\
\hline $\begin{array}{l}\text { Nurses and assistant } \\
\text { nurses were respectful }\end{array}$ & $3.73 / 0.55^{d}$ & $3.67 / 0.58$ & 0.11 & $3.79 / 0.53^{d}$ & $3.63 / 0.59$ & $<0.00 I^{\mathrm{c}}$ \\
\hline $\begin{array}{l}\text { Information on effects } \\
\text { and use of medicine }\end{array}$ & $3.31 / 0.89$ & $3.39 / 0.76$ & 0.27 & $3.34 / 0.87$ & $3.37 / 0.73$ & 0.57 \\
\hline $\begin{array}{l}\text { Physical-technical } \\
\text { conditions dimension }\end{array}$ & $3.23 / 0.66^{d}$ & $3.27 / 0.65^{\mathrm{e}}$ & 0.28 & $3.50 / 0.62^{\mathrm{d}}$ & $3.43 / 0.56^{\mathrm{e}}$ & 0.07 \\
\hline Food and drink I like & $3.20 / 0.92^{\mathrm{d}}$ & $3.10 / 0.83^{e}$ & 0.27 & $3.46 / 0.85^{d}$ & $3.27 / 0.75^{\mathrm{e}}$ & $<0.001^{\mathrm{c}}$ \\
\hline $\begin{array}{l}\text { Access to necessary } \\
\text { apparatus and equipment }\end{array}$ & $3.4 \mathrm{I} / 0.78^{\mathrm{d}}$ & $3.4 \mathrm{I} / 0.7 \mathrm{I}$ & 0.89 & $3.65 / 0.65^{d}$ & $3.48 / 0.68$ & $0.00 \mathrm{I}^{\mathrm{c}}$ \\
\hline Comfortable bed & $3.04 / 1.0^{d}$ & $3.30 / 0.76^{\mathrm{e}}$ & $<0.001^{\mathrm{c}}$ & $3.31 / 0.99^{d}$ & $3.48 / 0.65^{\mathrm{e}}$ & $0.005^{c}$ \\
\hline $\begin{array}{l}\text { Sociocultural } \\
\text { atmosphere } \\
\text { dimension }\end{array}$ & $3.21 / 0.67^{d}$ & $3.22 / 0.63$ & 0.47 & $3.54 / 0.57^{d}$ & $3.32 / 0.70$ & 0.27 \\
\hline $\begin{array}{l}\text { Talked to the doctors in } \\
\text { private }\end{array}$ & $2.87 / 1.2^{\mathrm{d}}$ & $3.18 / 1.0$ & $0.002^{c}$ & $3.56 / 0.8 \mathrm{I}^{\mathrm{d}}$ & $3.39 / 0.83$ & 0.07 \\
\hline
\end{tabular}

(Continued) 
Table 3 (Continued)

\begin{tabular}{|c|c|c|c|c|c|c|}
\hline \multirow[t]{2}{*}{ Care quality } & \multicolumn{3}{|c|}{ Old hospital - 2015, N=253 } & \multicolumn{3}{|c|}{ New hospital - 2016, N=324 } \\
\hline & $\begin{array}{l}\text { PR }^{\text {a }} \text { (Mean/ } \\
\text { SD) }\end{array}$ & $\begin{array}{l}\text { SI' } \\
\text { (Mean/ } \\
\text { SD) }\end{array}$ & $P$-value ${ }^{c}$ & $\begin{array}{l}\text { PR }^{\text {a }} \text { (Mean/ } \\
\text { SD) }\end{array}$ & $\begin{array}{l}\text { SI' } \\
\text { (Mean/ } \\
\text { SD) }\end{array}$ & $P$-value ${ }^{c}$ \\
\hline $\begin{array}{l}\text { Talked to the nurses in } \\
\text { private }\end{array}$ & $3.04 / 1.1^{\mathrm{d}}$ & $3.14 / 1.0^{\mathrm{e}}$ & 0.12 & $3.68 / 0.67^{d}$ & $3.40 / 0.8 \mathrm{I}^{\mathrm{e}}$ & $<0.00 I^{c}$ \\
\hline $\begin{array}{l}\text { Pleasant atmosphere on } \\
\text { the ward }\end{array}$ & $3.58 / 0.68^{d}$ & $3.53 / 0.64^{\mathrm{e}}$ & 0.27 & $3.67 / 0.66^{d}$ & $3.62 / 0.64^{\mathrm{e}}$ & 0.14 \\
\hline $\begin{array}{l}\text { Relatives and friends } \\
\text { treated well }\end{array}$ & $3.77 / 0.48^{d}$ & $3.61 / 0.6 I$ & $0.00 I^{c}$ & $3.85 / 0.40^{\mathrm{d}}$ & $3.63 / 0.57$ & $<0.00 I^{\mathrm{c}}$ \\
\hline $\begin{array}{l}\text { Care determined by } \\
\text { own requests and needs }\end{array}$ & $3.00 / 0.98^{d}$ & $3.28 / 0.80$ & $<0.00 I^{c}$ & $3.36 / 0.82^{d}$ & $3.28 / 0.83$ & 0.26 \\
\hline $\begin{array}{l}\text { Fellow patients gave } \\
\text { good support }\end{array}$ & $3.05 / 1.1$ & $2.75 / 1.1$ & $0.004^{c}$ & $3.06 / 0.95$ & $2.90 / 1.10$ & 0.33 \\
\hline $\begin{array}{l}\text { Fellow patients } \\
\text { helped to understand } \\
\text { information }\end{array}$ & $2.57 / 1.2^{\mathrm{d}}$ & $2.57 / 1 . I^{b}$ & 0.58 & $3.18 / 0.96^{d}$ & $3.05 / 1.02^{\mathrm{e}}$ & 0.74 \\
\hline
\end{tabular}

Notes: a'Scale could range from I (do not agree at all) to 4 (completely agree). bScale could range from I (little or no importance) to 4 (very highest importance). cP $\leq 0.05$. dPR scores 2015 were significantly lower than PR scores 2016. ${ }^{\mathrm{e} S I}$ scores 2015 were significantly lower than SI scores 2016.

Abbreviations: PR, perceived reality; SI, subjective importance.

The scores on the care personnel dimensions identityoriented approach and medical-technical competence were higher in the new hospital, even though not significantly higher than in the old hospital. This was also the results from the study by Siddiqui et $a{ }^{25}$ where no significant differences in relation to health care personnel were found. One might ask whether the technology gives the health professionals the opportunity of spending more time with the patients, which was one of the intentions with the introduction of technology. One explanation might be that when this study was conducted approximately 10 months after moving into the new, high-tech hospital health care professionals might still be struggling with adjusting to the changes in work processes. The personnel might have been less efficient in providing care while they adjust. A majority of the health care personnel in hospitals are registered nurses (RNs). A previous study found that there is a need to improve the quality of the nurse-patient interaction so as to facilitate individualized care independent of hospitals' organizational variables. ${ }^{35}$ This may be difficult, as RNs at the same time experience a conflict between their desire to provide nursing care based on the patients' needs and preferences and factors such as cost-effectiveness policy and transparency goals for external accountability. ${ }^{36}$ Future research ought to examine what health care personnel believe that the impact of the new technology has been on their provision of care and, in addition, examine the health care personnel's views on how the systems could be improved to increase quality patient care.
On an item level, seven of the 27 items in the new hospital showed high-quality balance with PR scores significantly higher than the respective SI scores. Within the dimension of the identity-oriented approach, the patients showed high scores on the nurse and assistant nurse commitment toward them and doctors, nurses, and assistant nurses showed them respect. This study found higher perceived care quality compared to Muntlin et al's ${ }^{37}$ study from 2006 using the same questionnaire. They found that more than $20 \%$ of the patients felt that the nurses did not show any interest in their life situation. Our results are, however, in line with results from a Nordic study in which the patients showed high scores on nursing care..$^{38}$ Being respectful and showing commitment are important aspects of person-centered care. ${ }^{39}$ Patients' experiences of person centeredness were highlighted in one study as having an influential role in patients' care quality experiences. ${ }^{3}$ Our results are, therefore, promising for developing a more person-centered approach in hospital and hence increasing the quality of care from the patients' perspective.

Within the environmental dimension physical-technical conditions, the patients showed high PR scores on having access to the apparatus and equipment that was necessary for their medical care and receiving food and drink that they liked. This is as expected, since the hospital trust is brand-new, with entirely new equipment, and also in line with previous research. ${ }^{25}$ Within the environmental dimension sociocultural atmosphere, the patients showed high PR scores on the items concerning the fact that their relatives and friends were treated well and that they could talk to the 
nurse in private when they wanted to. In the new hospital, there are only single rooms and, as such, the patients can have families and friends staying and they can talk in private with the nurses and doctors. However, our results show that the number of patients staying in the corridor is the same in the new hospital as in the old one, that is, one in 10 patients. This may threaten the patients' privacy. Results of a review on healing environment found that patients staying in multiple bed rooms and patients staying in a waiting area felt less secure and less able to control social encounters. ${ }^{40}$ The main problem in the waiting area was overhearing conversations at the reception desk, which can be comparable to receiving information when staying in a bed in the corridor.

On five items, the patients scored significantly higher on SI than PR, indicating a deficit in care quality, and areas for quality improvement. Within the care personnel's medicaltechnical competence dimension, the deficit concerned receiving effective pain relief and being given an examination and treatment within an acceptable waiting time. Muntlin et $\mathrm{al}^{37}$ found that $20 \%$ of patients reported that they did not receive effective pain relief, and Fröjd et $\mathrm{al}^{41}$ found the same, in addition to $22 \%$ not being given an examination and treatment within an acceptable waiting time. In contrast, an American study found that greater health information technology investments in hospitals were associated with shorter waiting times during hospitalization. ${ }^{42}$ The hospital participating in our study is the most high-tech hospital in Norway, but at the same time, it is the fourth largest emergency hospital. This might be associated with an increase in waiting times, because critically ill patients must be prioritized.

Within the care personnel's identity-oriented approach dimension, the quality deficit concerned receiving useful information on self-care and on which doctors were responsible for their care. This is in line with results from Muntlin et al's ${ }^{37}$ and Fröjd et al's ${ }^{41}$ studies. Both studies were made using the QPP questionnaire. Skudal et $\mathrm{al}^{38}$ using the NORPEQ questionnaire found similar results in three different countries where the lowest scores were given to items relating to information on tests and examinations. These systems contribute to a more efficient logistics, while relieving health professionals from this job allowing them the opportunity to spend more quality time with the patients.

Having a comfortable bed received higher scores on SI than PR indicating a quality deficit. Fröjd et $\mathrm{al}^{41}$ found that $22 \%$ of the patients were dissatisfied with the hospital beds in their study. One possible explanation might be that the hospital beds, old or new, are standard beds not adapted to the individual patient with their different body shapes and, therefore, different needs during rest and sleep. Another explanation might be the patients in the new hospital stay in single rooms with no other company than their own thoughts and feelings and with no natural common area to meet other patients for sharing worries and concerns. The bed can possibly be the one thing to concentrate on.

\section{Methodological considerations}

The analyses were run at a group level as the respondents were not the same in the two samples. Independent $t$-tests and Chi-squared tests were run to test for potential differences. The results showed no significant differences between the samples except for more men answering the questionnaire in 2016 than in 2015. The respondents in 2016 also showed an increase in their SI in the physical-technical conditions, which may reflect a general trend toward strengthened consciousness among patients as the hospital is new and modern. ${ }^{43}$

The respondents were mostly younger people. The nurses on the wards/bed courts were responsible for asking patients to participate in the study. They assessed which patients could be asked based on the patient's physical and mental health. Therefore, patients who were critically ill, or in a palliative phase, had mental disorders such as dementia and very poor mental health and were not invited to take part in the study. The results from our study cannot be generalized to these groups of patients. The problem concerning the inclusion of these groups of patients are well known from other studies. ${ }^{13}$ The nurses may have assessed a patient's condition differently, so that patients included on one ward/bed court may not have been included on another ward/bed court. The authors tried to make the nurses' assessment as similar as possible by giving oral information and written guidelines about the inclusion criteria to the responsible nurses and further on to offer to assist the patient in completing the questionnaire.

The patients answered the questionnaire on the day before or on the day of discharge from hospital. This might be a threat to credible answers. Patients may have felt that they had to give more positive answers than they would have after discharge. They may have been unsure of possible consequences for their health care. To avoid this, the patients were asked to fill in the questionnaire when they were alone and return it in a sealed envelope. One positive aspect of answering the questionnaire before discharge is that the experiences of health care quality are still fresh and not biased by the passing of time or influenced by relatives and friends. Results that have studied the possible effect of survey timing show that the effect may also depend on the nature of the patients' illness and the extent of their recovery. ${ }^{6}$ 
The Cronbach's $\alpha$ for the quality of care dimension scales in the questionnaire ranged between 0.54 and 0.91 , which was quite similar with scores found in previous studies. The Cronbach's $\alpha$ for the physical-technical dimension (0.54) was the exception. Previous studies have higher scores. ${ }^{27,29}$ The Cronbach's $\alpha$, however, is known to be lower for dimension scales that comprise fewer items. ${ }^{44}$ The physical-technical dimension scale included only three items. It is important to collect data on the patients' perceptions of the quality of the hospital's physical-technical conditions, but the results must be interpreted with care. The questionnaire (QPP) is, however, validated and often used. . $^{41,45,46}$

One potential limitation might be that the patients' care quality ratings in 2015 were negatively affected by a sense of decay in the old hospital right before the move. The results from 2016 must therefore be interpreted with care, and it could be valuable to repeat the study after a year to see if the increase in patients' care quality ratings continues.

Research shows that conducting a patient survey and using the results to improve the quality of health care are two different processes. ${ }^{47}$ The usefulness of patient surveys depends on the interaction between these two processes, and there seems to be a need for developing guidelines on how to use these data in quality work on wards/bed courts. ${ }^{48}$

\section{Conclusion}

Being a patient in a new high-tech hospital has increased patients' perceptions of care quality, but the increase in care QPP was associated with improved environmental conditions, and no significant improvement in care quality was associated with the health care personnel. Health care personnel needs time to adjust to changes in work processes. Future quality improvement activities should examine how the features of a high-tech hospital can be utilized to support health care personnel to be more attentive to the individual care needs of each patient. The results gave valuable information for quality improvement in clinical practice based on the patients' perspective.

\section{Ethical considerations and approval}

The study followed the principles of the Declaration of Helsinki. ${ }^{49}$ The respondents were verbally informed and given written information stating the purpose of the study that the data would be handled confidentially and that they had the right to withdraw at any time without any consequences for them. Informed consent to participate was considered given when the respondent returned a completed questionnaire. The study was approved by the Norwegian Social Science Data Services (reference number 44034).

\section{Acknowledgment}

The authors are grateful to the respondents who participated and shared their experiences on health care quality when being hospitalized.

\section{Author contributions}

VAG and AKH designed the study. All authors collected the data, contributed toward data analysis, drafting and revising the paper and agree to be accountable for all aspects of the work. All authors read and approved the final manuscript.

\section{Disclosure}

The authors report no conflicts of interest in this work.

\section{References}

1. Donabedian A. The Definition of Quality and Approaches to its Assessment. Ann Arbor, MI: Health Administration Press; 1980.

2. Lov om spesialisthelsetjenesten m. m. Vol 59/2000. Oslo: Sosial- og helsedepartementet; 2000

3. Edvardsson D, Watt E, Pearce F. Patient experiences of caring and person-centredness are associated with perceived nursing care quality. J Adv Nurs. 2017;73(1):217-227.

4. Aiken LH, Sermeus W, Van den Heede K, et al. Patient safety, satisfaction, and quality of hospital care: cross sectional surveys of nurses and patients in 12 countries in Europe and the United States. BMJ. 2012;344:e1717.

5. You LM, Aiken LH, Sloane DM, et al. Hospital nursing, care quality, and patient satisfaction: cross-sectional surveys of nurses and patients in hospitals in China and Europe. Int J Nurs Stud. 2013;50(2):154-161.

6. Crow R, Gage H, Hampson S, et al. The measurement of satisfaction with healthcare: implications for practice from a systematic review of the literature. Health Technol Assess. 2002;6(32):1-244.

7. Sofaer S, Firminger K. Patient perceptions of the quality of health services. Annu Rev Public Health. 2005;26:513-559.

8. Wilde B, Starrin B, Larsson G, Larsson M. Quality of Care from a Patient Perspective. Scand J Caring Sci. 1993;7(2):113-120.

9. Danielsen K, Garratt AM, Bjertnaes ØA, Pettersen KI. Patient experiences in relation to respondent and health service delivery characteristics: a survey of 26,938 patients attending 62 hospitals throughout Norway. Scand J Public Health. 2007;35(1):70-77.

10. Grøndahl VA, Karlsson I, Hall-Lord ML, Appelgren J, Wilde-Larsson B. Quality of care from patients' perspective: impact of the combination of person-related and external objective care conditions. J Clin Nurs. 2011;20(17-18):2540-2551.

11. Jenkinson C, Coulter A, Bruster S, Richards N, Chandola T. Patients' experiences and satisfaction with health care: results of a questionnaire study of specific aspects of care. Qual Saf Health Care. 2002;11(4):335-339.

12. Larsson G, Wilde-Larsson B. Quality of care and patient satisfaction: a new theoretical and methodological approach. Int J Health Care Qual Assur. 2010;23(2):228-247.

13. Grøndahl VA, Fagerli LB. Nursing home care quality: a cluster analysis. Int J Health Care Qual Assur. 2017;30(1):25-36.

14. Thorne L, Ellamushi H, Mtandari S, McEvoy AW, Powell M, Kitchen ND. Auditing patient experience and satisfaction with neurosurgical care: results of a questionnaire survey. Br J Neurosurg. 2002;16(3):243-255.

15. Vukmir RB. Customer satisfaction. Int J Health Care Qual Assur Inc Leadersh Health Serv. 2006;19(1):8-31.

16. Sjetne IS, Veenstra M, Ellefsen B, Stavem K. Service quality in hospital wards with different nursing organization: nurses' ratings. J Adv Nurs. 2009;65(2):325-336. 
17. Aiken LH, Clarke SP, Sloane DM, Sochalski J, Silber JH. Hospital nurse staffing and patient mortality, nurse burnout, and job dissatisfaction. JAMA. 2002;288(16):1987-1993.

18. Henderson A, Caplan G, Daniel A. Patient satisfaction: the Australian patient perspective. Aust Health Rev. 2004;27(1):73-83.

19. Otani K, Waterman B, Faulkner KM, Boslaugh S, Dunagan WC. How patient reactions to hospital care attributes affect the evaluation of overall quality of care, willingness to recommend, and willingness to return. J Healthc Manag. 2010;55(1):25-37; discussion 38.

20. Shen HC, Chiu HT, Lee PH, Hu YC, Chang WY. Hospital environment, nurse-physician relationships and quality of care: questionnaire survey. J Adv Nurs. 2011;67(2):349-358.

21. Grøndahl VA, Wilde-Larsson B, Hall-Lord ML, Karlsson I. A pattern approach to analysing patients' satisfaction and quality of care perceptions in hospital. Int J Person Center Med. 2011;1(4):766-775.

22. Findik UY, Unsar S, Sut N. Patient satisfaction with nursing care and its relationship with patient characteristics. Nurs Health Sci. 2010;12(2):162-169.

23. Alvaro C, Wilkinson AJ, Gallant SN, Kostovski D, Gardner P. Evaluating intention and effect: The impact of healthcare facility design on patient and staff well-being. HERD. 2016;9(2):82-104.

24. Lavela SL, Etingen B, Hill JN, Miskevics S. Patient perceptions of the environment of care in which their healthcare is delivered. HERD. 2016;9(3):31-46.

25. Siddiqui ZK, Zuccarelli R, Durkin N, Wu AW, Brotman DJ. Changes in patient satisfaction related to hospital renovation: experience with a new clinical building. $J$ Hosp Med. 2015;10(3):165-171.

26. Mønsted T, Fossum K. Building for the Next Generation: Practical Challenges for Platformization at a Norwegian Hospital. Norway: University of Oslo: 2018.

27. Wilde Larsson B, Larsson G. Development of a short form of the Quality from the Patient's Perspective (QPP) questionnaire. J Clin Nurs. 2002;11(5):681-687.

28. Larsson G, Wilde-Larsson B. Quality improvement measures based on patient data: some psychometric issues. Int J Nurs Pract. 2003;9(5):294-299.

29. Larsson BW. Patients' views on quality of care: age effects and identification of patient profiles. J Clin Nurs. 1999;8(6):693-700.

30. Henoch I, Lövgren M, Wilde-Larsson B, Tishelman C. Perception of quality of care: comparison of the views of patients' with lung cancer and their family members. $J$ Clin Nurs. 2012;21(3-4):585-594.

31. Field A. Discovering Statistics Using IBM SPSS Statistics. 4th ed. UK: Sage; 2013

32. Tabachnick BG, Fidell LS. Using Multivariate Statistics. 6th ed. Boston, MA: Allyn \& Bacon/Pearson Education; 2007.

33. Polit DF, Beck CT. Nursing Research: Generating and Assessing Evidence for Nursing Practice. 8th ed. Baltimore, MD: Lippincott Williams \& Wilkins; 2008.
34. MacAllister L, Zimring C, Ryherd E. Environmental variables that influence patient satisfaction: A review of the literature. HERD. 2016;10(1): 155-169.

35. Suhonen R, Välimäki M, Katajisto J, Leino-Kilpi H. Hospitals' organizational variables and patients' perceptions of individualized nursing care in Finland. J Nurs Manag. 2007;15(2):197-206.

36. Kieft RA, de Brouwer BB, Francke AL, Delnoij DM. How nurses and their work environment affect patient experiences of the quality of care: a qualitative study. BMC Health Serv Res. 2014;14:249.

37. Muntlin A, Gunningberg L, Carlsson M. Patients' perceptions of quality of care at an emergency department and identification of areas for quality improvement. J Clin Nurs. 2006;15(8):1045-1056.

38. Skudal KE, Garratt AM, Eriksson B, Leinonen T, Simonsen J, Bjertnaes OA. The Nordic Patient Experiences Questionnaire (NORPEQ): crossnational comparison of data quality, internal consistency and validity in four Nordic countries. BMJ Open. 2012;2(3):e000864.

39. McCormack B, Dewing J, McCance T. Developing person-centred care: addressing contextual challenges through practice development. Online J Issues Nurs. 2011;16(2):3.

40. Huisman ERCM, Morales E, van Hoof J, Kort HSM. Healing environment: A review of the impact of physical environmental factors on users. Build Environ. 2012;58:70-80.

41. Fröjd C, Swenne CL, Rubertsson C, Gunningberg L, Wadensten B. Patient information and participation still in need of improvement: evaluation of patients' perceptions of quality of care. J Nurs Manag. 2011;19(2):226-236.

42. Lee J. The impact of health information technology on disparity of process of care. Int J Equity Health. 2015;14:1-7.

43. Larsson G, Wilde-Larsson B. Changes over time in the importance patients ascribe to different aspects of care: on the need to improve person-centeredness. Int J Person Center Med. 2012;2(3):482-490.

44. Streiner DL, Norman GR, Cairney J. Health Measurement Scales: A Practical Guide to their Development and Use. 5th ed. USA: Oxford University Press; 2015.

45. Larsson BW, Larsson G, Chantereau MW, von Holstein KS. International comparisons of patients' views on quality of care. Int $J$ Health Care Qual Assur Inc Leadersh Health Serv. 2005;18(1):62-73.

46. Rahmqvist M, Bara AC. Patient characteristics and quality dimensions related to patient satisfaction. Int J Qual Health Care. 2010;22(2):86-92.

47. Patwardhan A, Spencer CH. Are patient surveys valuable as a serviceimprovement tool in health services? An overview. J Healthc Leadersh. 2012;4:33-46.

48. Haugum M, Danielsen K, Iversen HH, Bjertnaes O. The use of data from national and other large-scale user experience surveys in local quality work: a systematic review. Int J Qual Health Care. 2014;26(6):592-605.

49. Millum J, Wendler D, Emanuel EJ. The 50th anniversary of the Declaration of Helsinki: progress but many remaining challenges. JAMA. 2013;310(20):2143-2144
Journal of Multidisciplinary Healthcare

\section{Publish your work in this journal}

The Journal of Multidisciplinary Healthcare is an international, peerreviewed open-access journal that aims to represent and publish research in healthcare areas delivered by practitioners of different disciplines. This includes studies and reviews conducted by multidisciplinary teams as well as research which evaluates the results or conduct of such teams or health

\section{Dovepress}

care processes in general. The journal covers a very wide range of areas and welcomes submissions from practitioners at all levels, from all over the world. The manuscript management system is completely online and includes a very quick and fair peer-review system. Visit http://www.dovepress.com/ testimonials.php to read real quotes from published authors. 